\title{
MATH GAMES FOR ONE PLAYER
}

\author{
P. Beremlijski, P. Vondráková, M. Litschmannová, R. Mařík \\ VŠB - Technical University of Ostrava (CZECH REPUBLIC)
}

\begin{abstract}
The aim of the paper is to introduce mathematical interactive games created with the support of the STEM4youth project $(2016$ - 2018). The games were designed for individuals and also for two competing players or two competing teams and they are distributed as PDF files. In the paper we focus on the games for one player - the Funny picture game and the Puzzle game. Finally, the experience with similar games (predecessors of the STEM4youth games) in Czech schools is also discussed.
\end{abstract}

Keywords: math interactive games, PDF, games for one player, Funny picture game, Puzzle game.

\section{INTRODUCTION}

Mathematical interactive games were created by the authors of this article (members of Department of Applied Mathematics, Faculty of Electrical Engineering and Computer Science) with the support of the STEM4youth project (see [1]). The project is focused on a popularization of STEM subjects among young people - mathematics, physics, medicine, chemistry, astronomy, engineering and citizen science.

Educational games constitute an important class of methods in teaching on all levels of education. These games develop key competences and stimulate creativity and interest in the topic. In the STEM4youth project we authored educational games focused on training and strengthening mathematical skills. These games help in revision and better understanding of math topics. The educational materials introduced in this article are based on the ideas described in the papers [2], [3] and [4].

Authors of the article created 311 interactive games which are designed for individuals or for two competing players/teams. A database of 1767 multiple-choice questions was used for design of these games. The database comes from a translation of a national Czech project Matematika s radostí (The Joy of Math, 2012 - 2015) [5]. The questions included in this database have been designed by a team of secondary school lecturers and reviewed by the staff of Department of Applied Mathematics.

According to the number of players it is possible to divide all the games into two groups. In the first group are included the games for two players (the Jeopardy game and the Triangle game) which are discussed in the article [6]. In the second group are games for one player (the Puzzle game and Funny picture game) and they are going to be described in the forthcoming paragraphs.

By the topics all games are divided into thirteen areas which cover the secondary school mathematic courses in the major part of Europe. These areas are listed together with the corresponding number of games in Table 1. Such a division of the games is also on the website of the project.

\section{GAMES FOR ONE PLAYER}

The games for one player are intended to consolidate and strengthen math knowledge obtained in the class and they can be used in the class or for home practice. Teachers can use the materials on an interactive whiteboard where the students choose the right solutions. An alternative is to present the materials using screen and data projector. In the latter case the students answer questions and the teacher marks their answer on a computer. If a computer lab is available, students can work independently and the teacher supervises and answers questions only. In all games the answers are randomized if the PDF is re-opened. In addition, in the Puzzle games the questions are randomized too. So, each student has an original version of the same game.

Students can use the games in their home practice as well. Thanks to interactivity and nice pictures, the practice is funnier than regular homework. 
Authors prepared short promotional videos for each type of these games that show a typical workflow during the playing the game. Links to the videos follow in the further parts of the article devoted to the description of these games.

Table 1. Numbers of the Puzzle games, the Funny picture games, the Jeopardy games and the Triangle games in each area and numbers of multiple-choice questions used in these games.

\begin{tabular}{|l|c|c|c|c|c|}
\hline \multicolumn{1}{|c|}{ Area } & $\begin{array}{c}\text { Puzzle } \\
\text { games }\end{array}$ & $\begin{array}{c}\text { Funny picture } \\
\text { games }\end{array}$ & $\begin{array}{c}\text { Jeopardy } \\
\text { games }\end{array}$ & $\begin{array}{c}\text { Triangle } \\
\text { games }\end{array}$ & $\begin{array}{c}\text { Multiple-choice } \\
\text { Questions }\end{array}$ \\
\hline Basics of math & 12 & 7 & 11 & 6 & 207 \\
\hline $\begin{array}{l}\text { Algebraic equations and } \\
\text { inequalities }\end{array}$ & 11 & 11 & 18 & 10 & 326 \\
\hline Functions & 13 & 8 & 12 & 5 & 214 \\
\hline Exponents and logarithms & 3 & 1 & 2 & 1 & 33 \\
\hline Trigonometry & 6 & 3 & 5 & 2 & 89 \\
\hline Triangle trigonometry & 6 & 2 & 4 & 2 & 61 \\
\hline Geometry & 4 & 2 & 3 & 1 & 54 \\
\hline Analytic geometry & 12 & 8 & 14 & 7 & 239 \\
\hline Complex numbers & 6 & 4 & 7 & 4 & 118 \\
\hline $\begin{array}{l}\text { Combinatorics, probability } \\
\text { and statistics }\end{array}$ & 6 & 4 & 6 & 3 & 109 \\
\hline Sequences and series & 9 & 4 & 7 & 3 & 125 \\
\hline Differential calculus & 6 & 4 & 6 & 3 & 106 \\
\hline Integral calculus & 7 & 3 & 5 & 2 & 86 \\
\hline Total & $\mathbf{1 0 1}$ & $\mathbf{6 1}$ & $\mathbf{1 0 0}$ & $\mathbf{4 9}$ & $\mathbf{1 7 6 7}$ \\
\hline
\end{tabular}

\subsection{Puzzle game}

The Puzzle game is a matching type game (puzzle). There are several variants of the user interface of these games. The most of them looks like the games shown in Fig. 1 (basic layout, all questions on the screen) or Fig. 2 (questions displayed as notebook pages with one question per page).

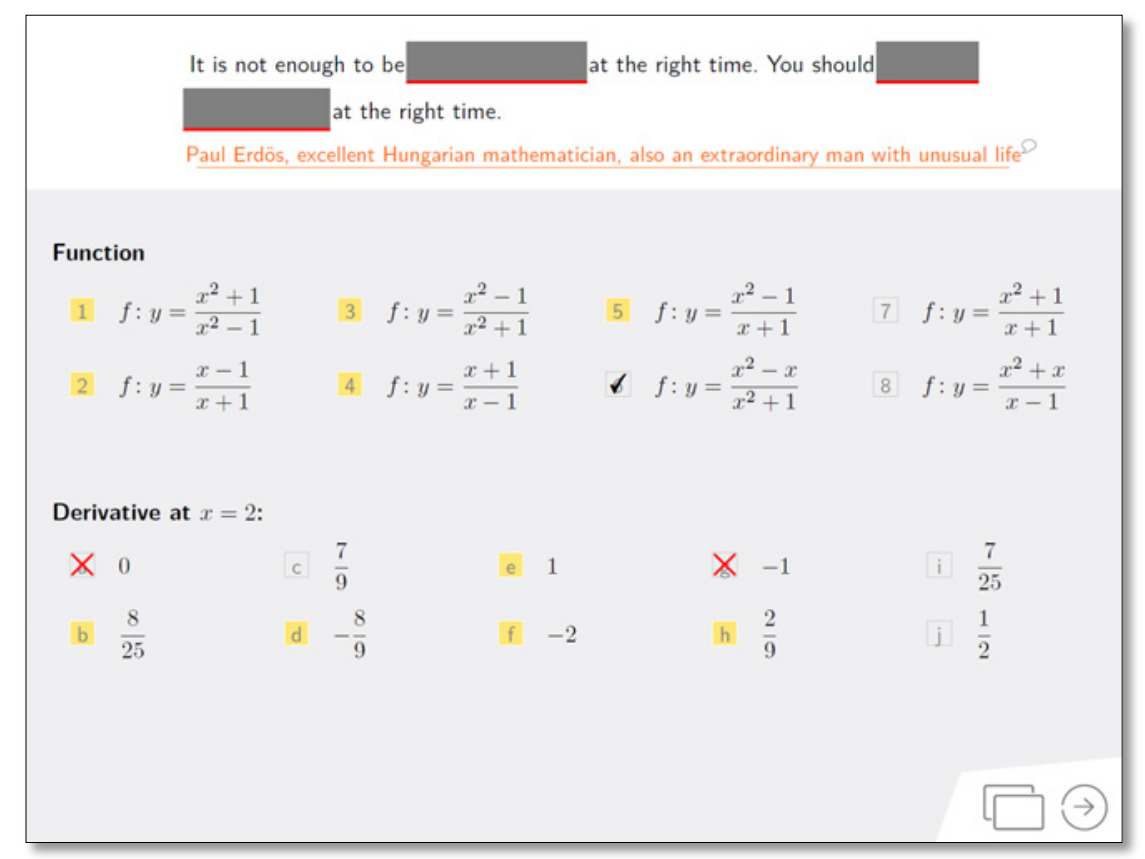

Figure 1. Basic layout of the Puzzle game. 
Step by step, the player selects a field with one question and consequently with one answer until matching all of the pairs. It doesn't matter in which order the player makes pairs. When matching the question and answer incorrectly, the player is given one penalty point, and continues in the game. Each correct pair uncovers a part of a hidden quotation of famous mathematician.

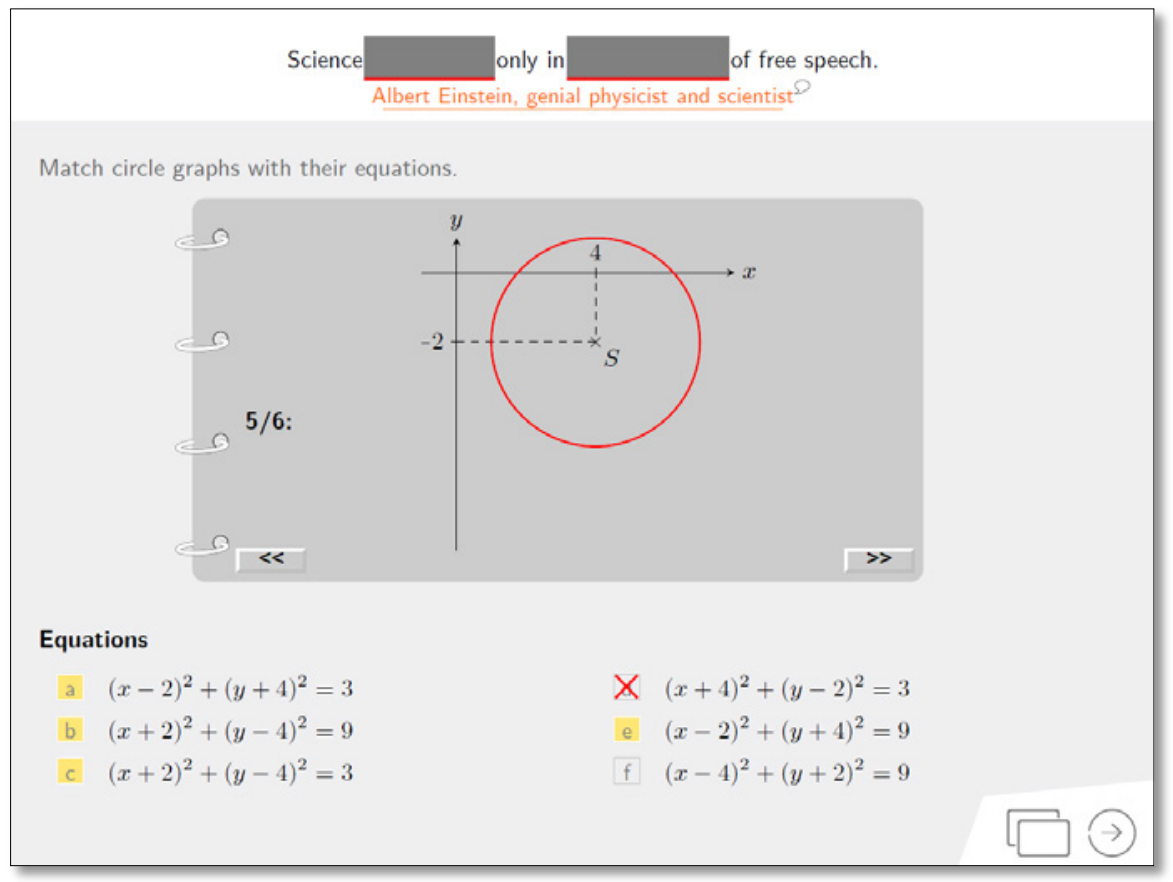

Figure 2. A variant of the Puzzle game with notebook.

These quotations of famous persons, mostly mathematicians or scientists are uncommon and attractive supplements in these game. A short story telling some notable aspects from the life and the work of this person is available as a popup window if the name is clicked (see Fig. 3 ).

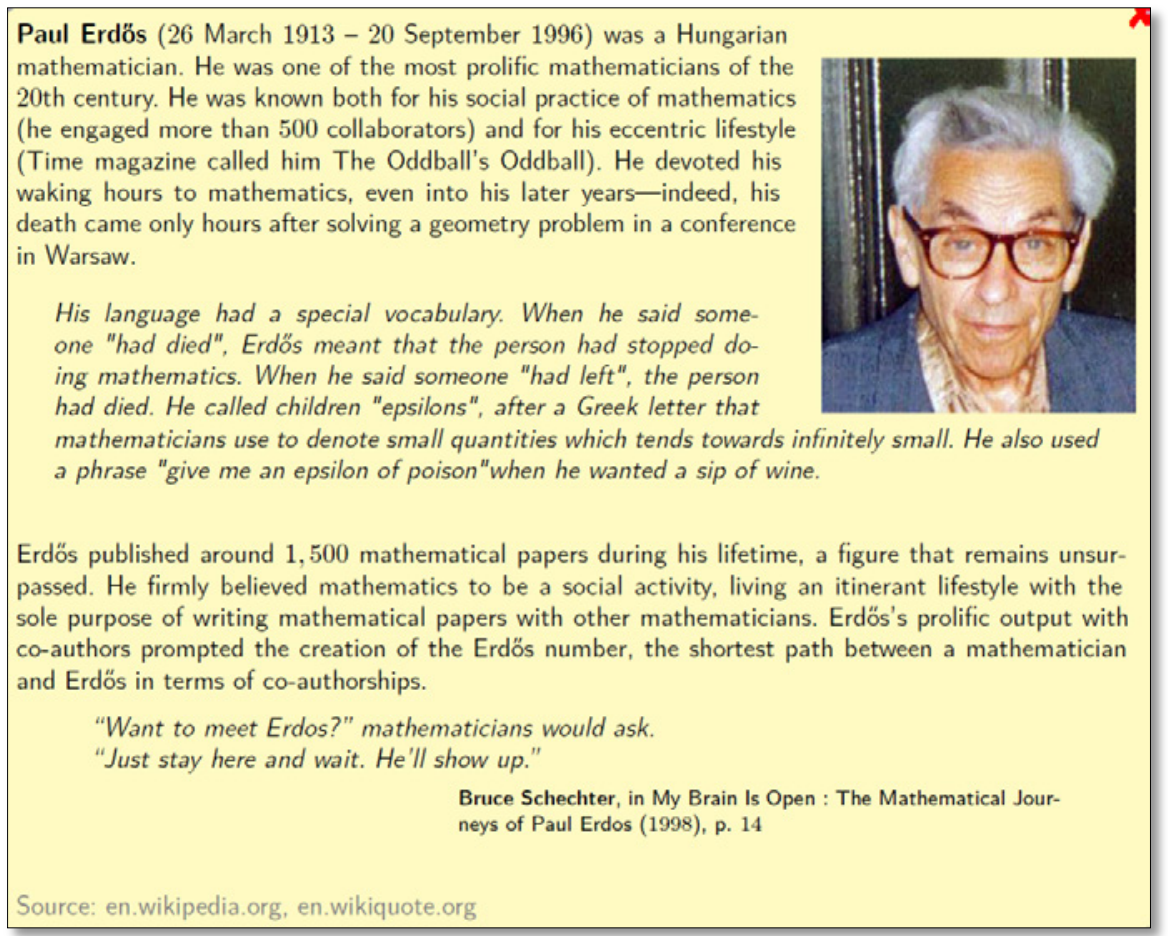

Figure 3. A short story from the life of Paul Erdös in the Puzzle game. 
Incorrect attempts are recorded during the game and evaluated at the end. According to the number of incorrect attempts, an informal comment is shown to the student. This gives the feedback to the player (see Fig. 4). For this purpose, authors prepared list of 12 different faces and about 30 different things to say instead of "good job".

Video: https://youtu.be/j-2CmI5MkKI
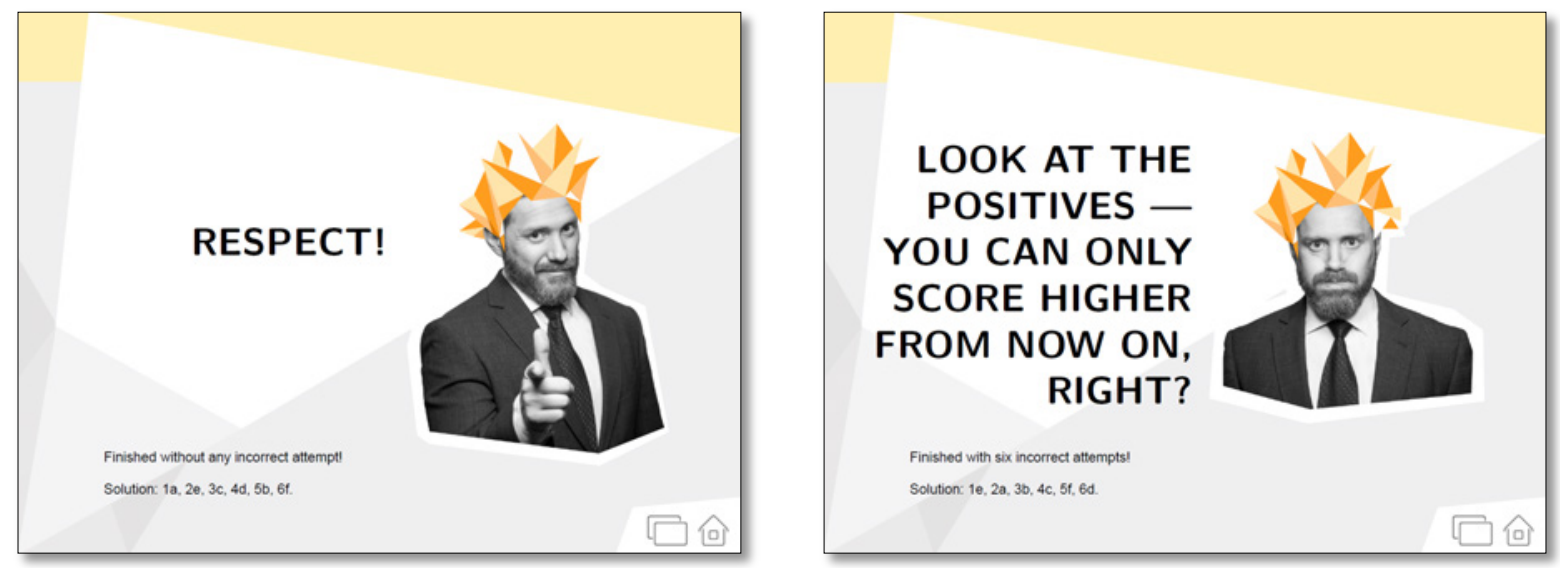

Figure 4. Evaluation of the Puzzle game - the best result (on the left) and a bad result (on the right).

\subsection{Funny picture game}

The Funny picture games (see Fig. 5) are quizzes with multiple-choice questions. Funny and interesting part of the game is that students by answering the questions unhide parts of a hidden picture with math cartoon. Each game contains a small database of at least 13 multiple-choice questions (26 questions in average, 44 questions maximum) from one area. A random generator associates 12 questions from this database with fields which cover a rectangular area and hide the picture. The parts of the picture are uncovered by giving correct answer to the corresponding questions. The Funny picture games include a collection of 35 cartoons created exclusively for STEM4youth project by a Czech artist M. Musialová.

Video: https://youtu.be/AaQ2nTSf-D8

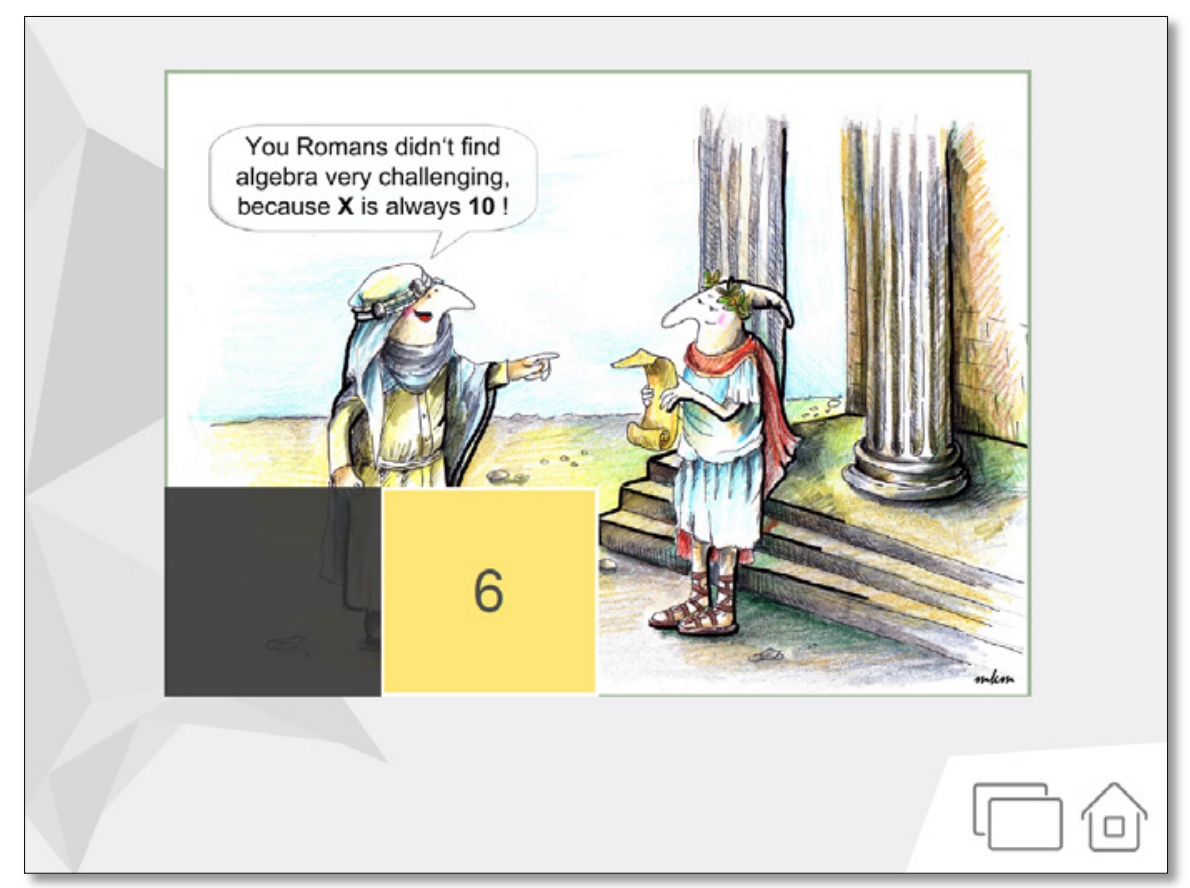

Figure 5. The Funny picture game. Most of the questions already answered. It remains to answer question 6. One question was not answered correctly (the dimmed square). 


\section{TECHNICAL DETAILS}

The interactive games created in the project have a common background: interactive PDF files. Really, all the games are nothing more than clever forms in PDF format. The PDF forms are popular in taxing and various government administration. The fact that the games are just regular PDF files simplifies the distribution and utilization of the games to a high degree, since it requires only common file manipulations. A small drawback of the interactivity is that the only PDF browser which is capable to run these games is Adobe Reader. The alternative PDF browsers with only partial support of PDF specifications which may be popular for static PDF files cannot be use, mainly due to the insufficient Javascript implementation.

The PDF files in the project are created by pdfLaTeX [7] and AcroTeX [8]. These tools are introduced in the paper [6]. In the forthcoming paragraphs we briefly explain how the interactivity has been achieved.

The main engine used to gain the interactivity in PDF files is the Javascript support. The PDF specification includes a variant of Javascript language which contain the core of this language and a custom set of additional commands and methods which can be used to manipulate objects used in PDF files, such as buttons, checkboxes, text fields and Optional Content Groups (see below).

The PDF specification allows to group parts of PDF files into so called Optional Content Group (OCG) and switch the visibility of the objects in this group either using the user interface in Adobe Reader or using Javascripts. This method has been used to hide and unhide objects, such as parts of the hidden quotation or the answers in the multiple-choice questions. However, to avoid the unintended changes in the visibility of the OCG's in the game and fooling the game we block the possibility to change OCG's state by user and only Javascript manipulation is allowed.

The PDF specification allows to store parts of PDF file as objects and refer to these objects. Consequently, the size of the resulting PDF file increases only a little if the same object is inserted several times. We utilized this method to show answers to multiple-choice questions in random order. Really, if a multiple-choice question has four possible answers, then there are four areas on the page where this answer is shown. In each area we have all fours possibilities in four overlapping OCG's. Only one of them is made visible as the PDF file is opened. A similar method is used to make a rich repertoire of messages at the end of the Puzzle game and on many other places - there are 6 levels of score with 12 different faces and about 30 different text messages (see Fig. 4).

Note that the effort to type the questions and build the game is not substantially harder than typing questions as plain text involving mathematics. Really, we enjoy the fact that the engine which writes the PDF file is a programming system pdfLaTeX and all the work to turn plain text into interactive game is done automatically. See also [6] for more information about advantages introduced by pdfLaTeX.

\section{EXPERIENCE WITH GAMES}

At the beginning of the year 2018 the STEM4youth project has not been finished yet and therefore the results of the evaluation of the materials have not been completed. However, the authors work in this area (interactive math games) since 2010. In the article we also share our experience with similar games (predecessors of the STEM4youth games) in Czech schools. Hereinafter we present the

outputs of collecting feedback from students of 5 Czech schools in 2015 . We also present a report on downloads of these materials from website of the project [5] in 2017.

\subsection{Questionnaire investigation}

The questionnaire investigation was realized in 2015 from January 28 to May 7. The respondents were students of Czech secondary schools: Grammar School, Ostrava-Hrabůvka; Secondary Grammar School of Otto Wichterle; Slavonic Grammar School, Olomouc; Secondary Technical School Přerov and Secondary School of Electrical Engineering Lipník nad Bečvou. These schools were included into piloting phase of the project [5].

The answers from 211 responders have been collated. The students indicated whether they use our interactive math games in class or for home practice. Further, they answered which types of materials of the project [5] they use. 


\subsubsection{Learning in class}

Overall 186 (84 \%) out of 221 respondents use the interactive materials from website of the project [5] in the mathematical lessons. The utilization in common class is summarized in Table 2. The numbers in parentheses are the relative frequencies of respondents who use the particular game in the group of respondents who use any game in the class (186).

Table 2. Using interactive math games in the class (results of online survey among 221 respondents).

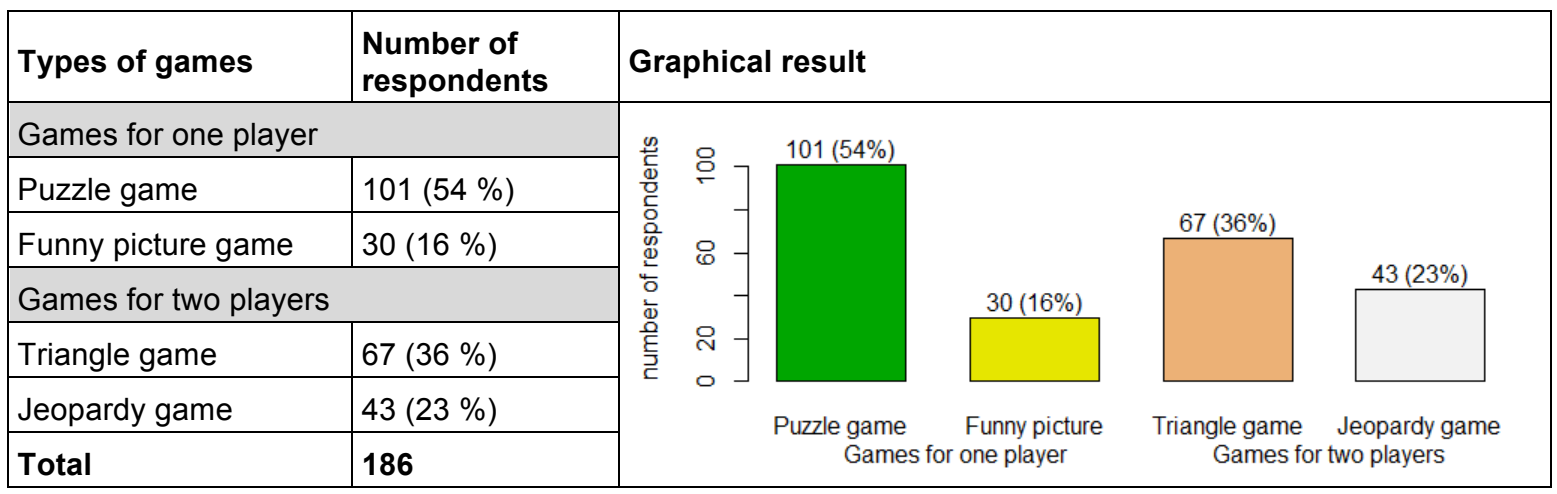

\subsubsection{Learning at home}

Total $119(54 \%)$ out of 221 respondents use the materials from website of the project [5] when working and learning at home. The data on utilization of particular types of materials are collected in Table 3.

The numbers in parentheses are the relative frequencies of respondents who use the particular game in the group of all respondents who use any game for home practice (119).

Table 3. Using interactive math games for home practice (results of online survey, 221 respondents).

\begin{tabular}{|c|c|c|c|c|c|c|}
\hline Types of games & $\begin{array}{l}\text { Number of } \\
\text { respondents }\end{array}$ & \multicolumn{5}{|c|}{ Graphical result } \\
\hline \multicolumn{2}{|l|}{ Games for one player } & \multirow{7}{*}{ 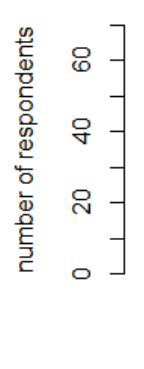 } & \multirow{2}{*}{$60(50 \%)$} & & \multirow[b]{3}{*}{$31(26 \%)$} & \multirow{3}{*}{$29(24 \%)$} \\
\hline Puzzle game & $60(50 \%)$ & & & & & \\
\hline Funny picture game & $20(17 \%)$ & & & \multirow{3}{*}{$20(17 \%)$} & & \\
\hline \multicolumn{2}{|l|}{ Games for two players } & & & & & \\
\hline Triangle game & $31(26 \%)$ & & & & & \\
\hline Jeopardy game & $29(24 \%)$ & & \multirow{2}{*}{\multicolumn{2}{|c|}{$\begin{array}{l}\text { Puzzle game Funny picture } \\
\text { Games for one player }\end{array}$}} & \multirow{2}{*}{\multicolumn{2}{|c|}{$\begin{array}{l}\text { Triangle game Jeopardy game } \\
\text { Games for two players }\end{array}$}} \\
\hline Total & 119 & & & & & \\
\hline
\end{tabular}

\subsection{Google Analytics data}

Google Analytics has been used to check the number of unique downloads ${ }^{1}$ of our electronic materials from the repository [5] in the period from January 1, 2017, to December 31, 2017 (see Tables 4 and 5). In total 8905 unique downloads were realized in this period. This total consist of $6841(77 \%)$ downloads of games for one player and $2064(23 \%)$ downloads of games for two players.

\footnotetext{
${ }^{1}$ Google Analytics increases the counter by 1 when the file is downloaded for the first time during the current session. The future downloads during the same session are ignored.
} 
Table 4. Number of unique downloads of games for one player (from January 1, 2017 to December 31, 2017).

\begin{tabular}{|l|c|c|}
\hline $\begin{array}{l}\text { Types of games } \\
\text { (for one player) }\end{array}$ & $\begin{array}{c}\text { Number of unique } \\
\text { downloads }\end{array}$ & Graphical result \\
\hline Puzzle game & $6473(95 \%)$ & \\
\hline $\begin{array}{l}\text { Funny picture } \\
\text { game }\end{array}$ & $368(5 \%)$ & $6473 ; 95 \%$ \\
\hline Total & $\mathbf{6 8 4 1}$ & \\
\hline
\end{tabular}

Table 5. Number of unique downloads of games for two players (from January 1, 2017 to December 31, 2017).

\begin{tabular}{|c|c|c|}
\hline $\begin{array}{c}\text { Types of games } \\
\text { (for two players) }\end{array}$ & $\begin{array}{c}\text { Number of unique } \\
\text { downloads }\end{array}$ & Graphical result \\
\hline Triangle game & $973(47 \%)$ & \\
\hline Jeopardy game & $1091(53 \%)$ & \\
\hline Total & \multicolumn{1}{|c|}{} \\
\hline
\end{tabular}

\section{SUMMARY}

The authors of the article designed a broad set of interactive math games which can be used to make math lessons and home practice more attractive.

Since the approach is quite unusual and involves several unique ideas, the technical background is explained briefly.

Results of questionnaire survey and numbers of downloads measured by Google Analytics show that games of this type became popular among students of partner schools in the Czech Republic. The games for one player are used more than games for two players.

\section{ACKNOWLEDGEMENTS}

The authors are supported by the European Union's Horizon 2020 research and innovation programme under grant agreement No. 710577.

\section{REFERENCES}

[1] Project STEM4youth, H2020, ID 710577. Promotion of STEM education by key scientific challenges and their impact on our life and career perspectives. Accessed 20 January, 2018. Retrieved from http://www.stem4youth.eu/ 
[2] R. Plch, P. Šarmanová, "Math games - interactive teaching materials in PDF format", Information and Communication Technology in Education. pp. 209-218, 2012.

[3] R. Mařík, R. PIch, P. Šarmanová, "Publishing interactive tests using AcroTEX" (in Czech), Zpravodaj Československého sdružení uživatelů TEXu, vol. 20, no. 4, pp. 266-291, 2010.

[4] R. Mařík, "PdfLaTeX and interactive electronic documents" (in Czech), Sborník příspěvků konference OSSConf 2013, pp. 17-24, 2013.

[5] Project The Joy of Math (in Czech), OPVK, reg. č. CZ.1.07/1.1.00/26.0042. Matematika $s$ radostí - vytvoření interaktivního vzdělávacího obsahu pro zvýšení zájmu o matematiku, radost z učení a zlepšení matematických dovedností. Accessed 20 January, 2018. Retrieved from http://msr.vsb.cz

[6] P. Vondráková, P. Beremlijski, M. Litschmannová, R. Mařík, "Math games for two players", INTED2018 Proceedings, 2018 (accepted).

[7] pdfTeX, Accessed 20 January, 2018. Retrieved from https://www.tug.org/applications/pdftex

[8] D. P. Story, AcroTeX eDucation bundle. Accessed 20 January, 2018. Retrieved from http://www.acrotex.net/aeb_index.php 